\title{
Media Tanam Akuaponik Dalam Ruang
}

\author{
Tahta Syajar Assaffah dan Primaditya \\ Departemen Desain Produk, Institut Teknologi Sepuluh Nopember (ITS) \\ e-mail:primadity@prodes.its.ac.id
}

\begin{abstract}
Abstrak-Pertanian urban telah menjadi tren yang mendukung gaya hidup dan lingkungan yang sehat didalam masyarakat perkotaan dimasa kini. Keterbatasan lahan pada masyarakat perkotaan merupakan salah satu dorongan untuk dilakukannya kegiatan tersebut. Salah satu cabang dari pertanian urban adalah akuaponik. Akuaponik memiliki beberapa keunggulan diantaranya adalah sirkulasi nutrisi organik yang dihasilkan oleh kotoran ikan sehingga kebutuhan nutrisi untuk tanaman dapat terpenuhi secara organik. Sistem akuaponik dapat bekerja dengan baik apabila tangki, biofilter, dan wadah tanaman dapat terkonfigurasi dengan baik dan seimbang. Berdasarkan produk yang muncul dipasaran, produk tersebut masih membutuhkan lahan luar rumah dalam memenuhi asupan cahaya pada tanaman. Selain itu bentuk produk dan material yang digunakan pada umumnya belum terlihat estetik. Hal ini seringkali terjadi kesulitan dalam peletakkan produk terutama pada pengguna yang ingin menjaga keindahan dalam rumah. Pengoptimalan perlu dilakukan terhadap unit akuaponik tanpa mengurangi fungsi sistem dan estetika pada ruang. Metode yang dilakukan dalam penilitian ini meliputi analisis kegiatan yang dimulai dari penyemaian sampai transplantasi tanaman untuk mendapatkan design requirement dan ide produk yang tepat. Kemudian tahap berikutnya ialah menyelaraskan bentuk produk dengan persona dan gaya ruang pengguna. Perancangan desain media tanam akuaponik dalam ruang ini mengaplikasikan teknologi yang mendukung kebutuhan pertumbuhan tanaman sehingga pengguna dapat terfasilitasi dengan baik. Selain itu media tanam akuaponik dirancang sebagai dekorasi ruang yang saling berintegrasi satu sama lain pada sistem dan memiliki karakter material yang mendukung estetika gaya ruang pengguna.
\end{abstract}

Kata Kunci-Akuaponik, Berkelanjutan, Dekorasi, Modular, Pertanian Kota.

\section{PENDAHULUAN}

$\mathrm{P}$ ERTANIAN urban telah menjadi tren yang mendukung gaya hidup dan lingkungan yang sehat didalam masyarakat perkotaan dimasa kini. Dengan keterbatasan lahan pada masyarakat perkotaan, hidroponik merupakan sebuah solusi bagi masyarakat perkotaan untuk mewujudkan hobi dalam bercocok tanam tersebut. Hidroponik adalah metode budidaya tanaman yang menggunakan larutan nutrisi mineral dalam air tanpa menggunakan tanah, istilah ini dikenal sebagai soilless culture[1]. Media tanam ini bersifat sebagai penunjang berdirinya tanaman dan dapat menyimpan air. Tanaman dapat mencukupi kebutuhannya melalui media tanam yang terintegrasi pada sumber air dan diserap oleh zona akar, baik bergerak maupun diam[2].

Akuaponik merupakan sebuah sistem lanjutan dari Hidroponik yang melibatkan deep water culture (DWC), nutrient film technique (NFT), dan media bed[3]. Perbedaan antara keduanya (Akuaponik dan Hidroponik) adalah terkait dengan sumber nutrisi pada tanaman. Hidroponik menggunakan sumber nutrisi kimia, sedangkan akuaponik memanfaatkan feses dan ammonia hasil dari metabolisme ikan[4]. Kemudian feses tersebut akan difiltrasi dan dekomposisi pada wadah tanaman oleh mikroba heterotrof menjadi berbagai unsur hara, sedangkan ammonia $\left(\mathrm{NH}_{3}\right)$ diubah menjadi nitrit oleh Nitrosomonas, selanjutnya Nitrit $\left(\mathrm{NO}_{2}\right)$ diubah oleh Nitrobacter[5]. Proses tersebut dibantu oleh media tanam hidroponik dan tanamannya yang berperan sebagai biofilter untuk menyaring dan membersihkan air dan disalurkan kembali ke dalam tangki ikan[6].

Kegiatan hidroponik pada umumnya diawali dengan rasa penasaran pada seseorang maupun sekelompok orang dengan metode maupun kualitas yang dihasilkan dari produk hidroponik. Namun tidak banyak orang yang dapat memahami betul cara bertanamnya sehingga kegagalan dapat memicu seseorang untuk berhenti[7]. Berdasarkan bentuk yang muncul dipasaran, instalasi media tanam akuaponik memiliki bentuk yang besar dan masih membutuhkan lahan dalam peletakkannya. Jika dilihat dari segi potensi akuaponik tersendiri, hijaunya tanaman dan hidupnya ikan pada sebuah sistem biosfer yang kecil tersebut dapat menghidupkan ruangan sekaligus dapat memproduksi pangan sendiri. Oleh karena itu perancangan desain media tanam pangan akuaponik dalam ruang ini dapat menunjang kebutuhan penghobi tanpa mengurangi fungsi pada sistem dan memberi estetika pada interior dalam rumah dengan memadukannya dalam kesatuan bentuk.

\section{URAIAN PENELITIAN}

\section{A. Metode Pengumpulan Data}

Metode yang digunakan dalam penelitian ini adalah metode penilitan kualitatif dan kuantitatif.

1) Pengambilan data kualitatif dilakukan dengan wawancara pada stakeholder. Narasumber yang diperoleh merupakan seorang ahli dibidang hidroponik dan pengajar kegiatan hidroponik.

2) Pengambilan data kuantitatif dilakukan dengan observasi dan partisipan aktif.

3) Pengambilan data melalui jurnal, artikel dan buku

\section{B. Tahap Studi dan Analisis}

Setelah proses pengumpulan data, dilakukan studi dan analisis pada beberapa aspek yang dibutuhkan sebagai berikut: 


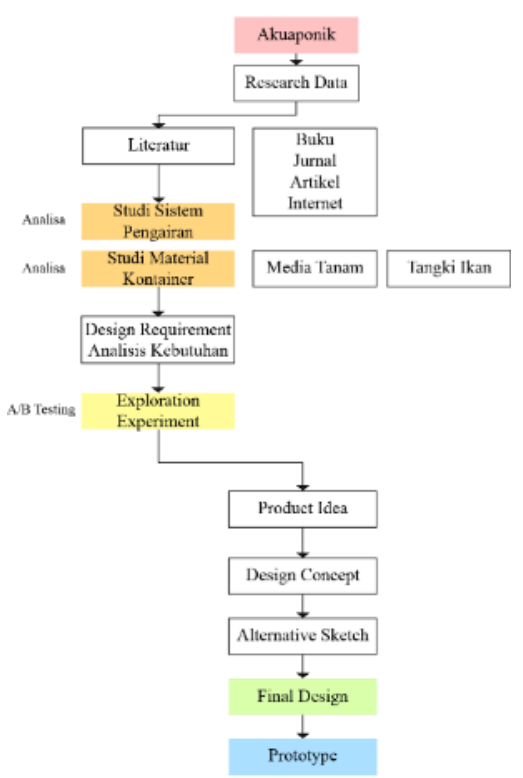

Gambar 1. Skema Penelitian.

1) Analisis Sistem Pengairan. Studi ini berfungsi untuk mengetahui sistem eksisting yang digunakan dalam pengoperasian akuaponik.

2) Studi Material dan Proses. Studi ini berfungsi untuk mengetahui proses material, kapabilitas dan batasanbatasan yang akan digunakan dalam mendesain

3) Design Requirement and Objective. Studi ini berfungsi untuk mengetahui angka dan ukuran anatomi produk terhadap studi dan analisis sistem pengairan, aspek biologis, dan aktivitas pengguna untuk dijadikan sebagai pertimbangan dalam mendesain.

\section{Tahap Prototyping}

Setelah proses studi dan analisis, dilakukan proses prototyping untuk mengimplementasikan rancangan ke dalam bentuk berwujud dan berfungsi yang dikembangkan dari ide terpilih dan terbaik. Prototype yang dihasilkan pada tahap ini merupakan prototype awal atau preliminary design untuk dapat digunakan dalam simulasi dan uji coba terhadap fungsinya.

\section{Skema Penelitian}

Terdapat beberapa tahapan dalam melakukan penelitian ini, yaitu tahap 1 - understand yang merupakan tahap pemahaman, tahap 2 - define dalam penentuan studi dan analisis, tahap 3 diverge untuk mendapatkan ide sebanyak mungkin, tahap 4 converge untuk pemilihan rancangan terbaik dari konsep, dan diakhiri dengan tahap implementasi prototype seperti Gambar 1.

\section{HASIL DAN PEMBAHASAN}

\section{A. Analisis Sistem Pengairan}

Analisis sistem pengairan bertujuan untuk mengetahui alur sirkulasi air dari wadah menuju akar tanaman serta komponenkomponen yang diperlukan dalam menunjang berjalannya sirkulasi tersebut. Selengkapnya dapat dilihat pada Tabel 1 .
Tabel 1.

Sistem pengairan metode akuaponik

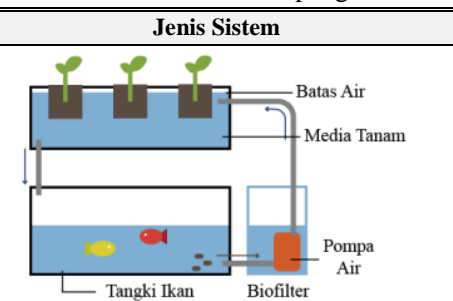

Keterangan

Nutrisi dipenuhi oleh feses ikan yang kemudian diubah didalam biofilter. Kemudian diteruskan kedalam media tanam untuk diserap.

Sistem Akuaponik Deep Water Culture

Kelebihan

- Tidak mudah mengalami penguapan

- Media dapat diangkat dan memudahkan pemanenan

- Dapat tahan dengan keadaan listrik yang tidak stabil

\section{Kekurangan}

- Filtrasi yang kompleks

- Unit memerlukan dimensi yang besar dan berat

- Tidak cocok untuk ditanami tanaman yang tinggi

- Memerlukan lebih dari 2 pompa

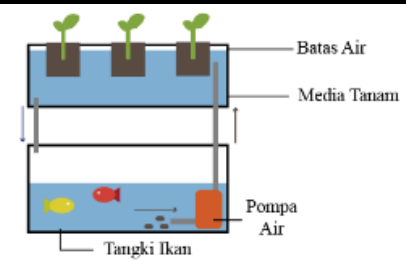

Perbedaan sistem pengairan pada kolom sebelumnya terletak pada biofilter yang tidak berdiri sendiri sehingga feses ikan disaring melalui media tanam.

Akuaponik Deep Water Culture: Small Scale

Kelebihan

Kekurangan

- Tidak mudah mengalami penguapan

- Media dapat diangkat dan memudahkan pemanenan

- Dapat tahan dengan keadaan listrik yang tidak stabil

- Tidak memerlukan wadah Biofilter

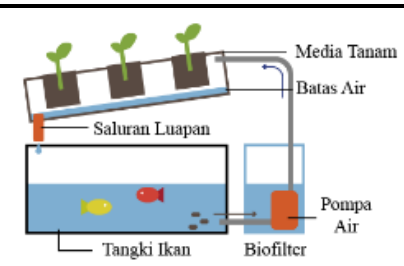

- Sistem tidak akan bekerja apabila tanaman tidak memiliki akar yang berguna sebagai filtrasi

- Tanaman hanya dapat dipanen satu persatu untuk menjaga akar melakukan filtrasi

Sama halnya dengan sistem NFT, nutrisi disedot oleh pompa dan ditampung kedalam biofilter kemudian diteruskan menuju media tanam yang dimiringkan.

Akuaponik Nutrient Film Technique

Kelebihan

- Tidak memerlukan tenaga yang besar dalam pemeliharaan

- Metode panen yang mudah

- Unit yang ringan

- Tingkat penguapan yang sedikit

- Tangki air yang dibutuhkan sedikit

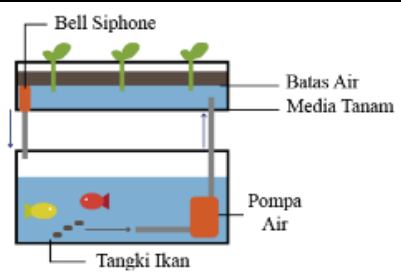

Kekurangan

- Filtrasi yang kompleks

- Sistem bergantung pada pompa air dan udara

- Temperatur air yang tidak konstan dapat memicu stress pada ikan

- Seringnya terjadi penyumbatan

Feses ikan tidak ditampung didalam biofilter, namun langsung tersaring didalam media tanam, kelebihan air akan di teruskan kembali kedalam tangki ikan melalui bell siphone.

Sistem Media Bed

\section{Kelebihan}

- Mudah dalam pemeliharaan

- Penggunaan listrik yang kecil

- Semua jenis tanaman dapat ditanam

- Tidak memerlukan biofilter

\section{Kekurangan}

- Transplantasi yang sulit

- Tingkat penguapan yang tinggi

- Tanaman dapat tumbuh tidak seragam 


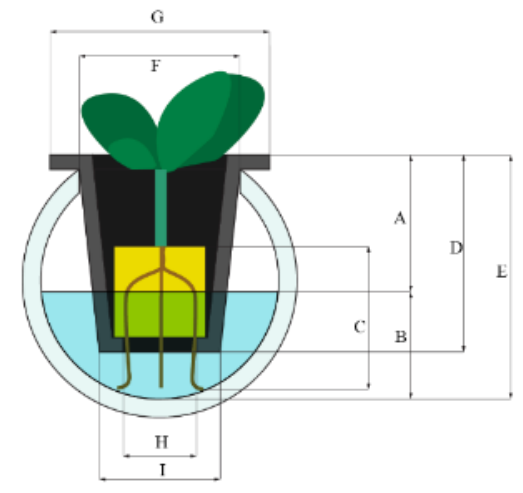

Gambar 2. Studi reverse engineering tampak samping.

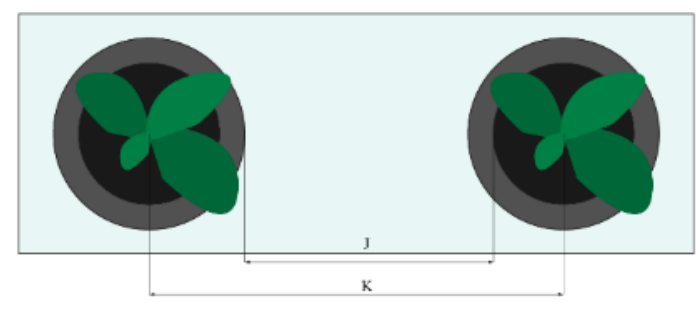

Gambar 3. Studi reverse engineering tampak atas.

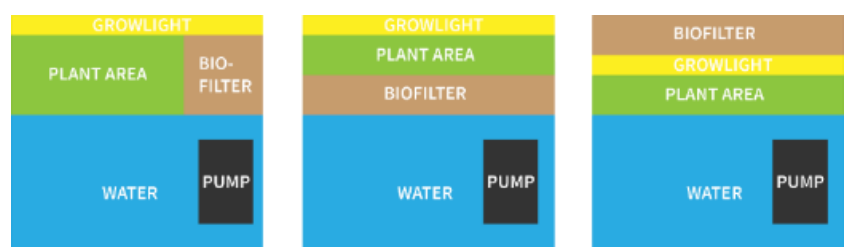

Gambar 4. Alternatif konfigurasi sistem pengairan.

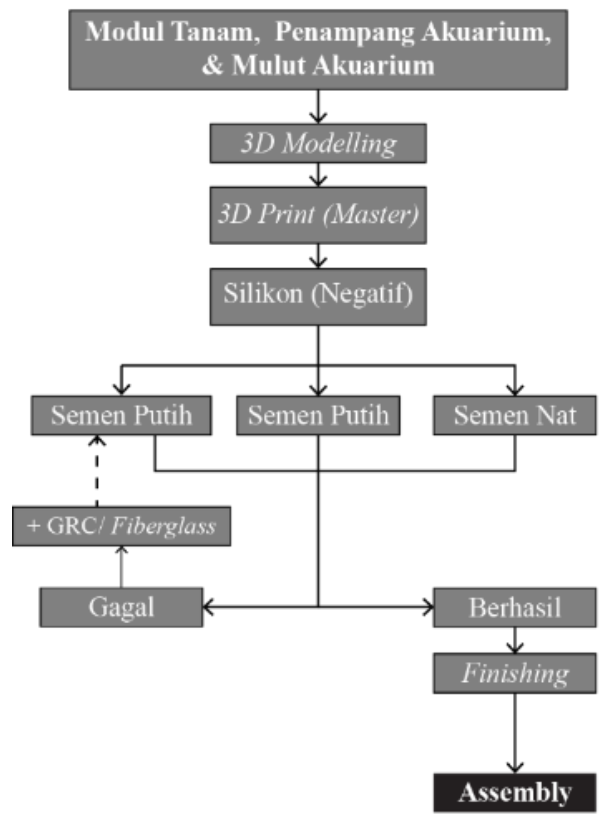

Gambar 5. Skema Proses Produksi.

\section{Kesimpulan pada Tabel 1:}

Berdasarkan analisis yang dilakukan, sistem eksisting yang dapat diadaptasi dan dijadikan acuan dalam mendesain adalah sistem media bed, dan akuaponik nutrient film technique.
Tabel 2.

Dimensi studi reverse engineering

\begin{tabular}{clr}
\hline \hline Label & \multicolumn{1}{c}{ Deskripsi } & \multicolumn{1}{c}{ Ukuran } \\
\hline A & Zona udara & $37.5 \mathrm{~mm}$ \\
B & Zona air & $30 \mathrm{~mm}$ \\
C & Zona akar & $40 \mathrm{~mm}$ \\
D & Tinggi netpot & $50 \mathrm{~mm}$ \\
E & Tinggi keseluruhan (diameter dalam) & $65 \mathrm{~mm}$ \\
F & Lebar lubang pada pipa & $44 \mathrm{~mm}$ \\
G & Lebar mulut luar netpot & $60 \mathrm{~mm}$ \\
H & Lebar lubang netpot & $20 \mathrm{~mm}$ \\
I & Lebar dasar netpot & $33 \mathrm{~mm}$ \\
J & Jarak antar lubang & $86 \mathrm{~mm}$ \\
K & Jarak tanam antar pusat lubang & $130 \mathrm{~mm}$ \\
\hline \hline
\end{tabular}

Tabel 3.

Analisis material wadah tanaman

\begin{tabular}{lccc}
\hline \hline \multicolumn{1}{c}{ Parameter } & Keramik & Kongkrit & Bambu \\
\hline Kemudahan Pengolahan & 4 & 3 & 2 \\
Bentuk & 4 & 4 & 2 \\
Tahan Air & 4 & 3 & 2 \\
Tahan Korosi & 3 & 4 & 3 \\
Kesesuaian Konsep & 2 & 3 & 4 \\
Massa Jenis & $\mathbf{1 7}$ & $\mathbf{1 7}$ & $\mathbf{1 3}$ \\
\hline Nilai Total & & &
\end{tabular}

Tabel 4.

Analisis material tangki ikan

\begin{tabular}{lccc}
\hline \multicolumn{1}{c}{ Parameter } & Kaca & Polyethylene & Akrilik \\
\hline Kemudahan Pengolahan & 2 & 4 & 3 \\
Bentuk & 2 & 3 & 4 \\
Biaya Produksi & 2 & 4 & 3 \\
Daya Lentur & 4 & 2 & 3 \\
Daya Tahan & 2 & 3 & 4 \\
Massa Jenis & $\mathbf{1 2}$ & $\mathbf{1 6}$ & $\mathbf{1 7}$ \\
\hline Nilai Total & & &
\end{tabular}

Tabel 5.

Analisis material penyangga lampu

\begin{tabular}{lccc}
\hline \hline \multicolumn{1}{c}{ Parameter } & Kayu & Alumunium & Bambu \\
\hline Kemudahan Pengolahan & 4 & 2 & 4 \\
Bentuk & 2 & 4 & 3 \\
Daya Tahan & 2 & 4 & 3 \\
Daya Lapuk & 2 & 4 & 3 \\
Tahan Air & 4 & 2 & 3 \\
Massa Jenis & $\mathbf{1 4}$ & $\mathbf{1 6}$ & $\mathbf{1 6}$ \\
\hline Nilai Total & & & \\
\hline \hline
\end{tabular}

Sistem tersebut dipilih berdasarkan kemudahan pemeliharaan, fleksibilitas dalam modifikasi, dan efisiensi ruang.

\section{B. Studi Reverse Engineering}

Reverse Engineering dilakukan untuk mendapatkan acuan terkait dalam konstruksi dan sistem yang bekerja. Penulis melakukan analisis pada sistem NFT (Nutrient Film Technique) untuk mencari tahu ukuran tiap-tiap elemen penting seperti zona akar, tinggi air, zona udara, dan komponen terkait. Penulis menjabarkannya dengan ilustrasi seperti Gambar $2-3$ dan Tabel 2.

\section{Kesimpulan pada Tabel 2:}

Berdasarkan hasil analisis tersebut, dapat diketahui beberapa poin penting seperti jarak tanam, zona akar, udara, dan air yang harus diperhatikan agar tanaman tidak berdesakan dan tidak 
Tabel 6.

Uji coba dan pengamatan desain awal

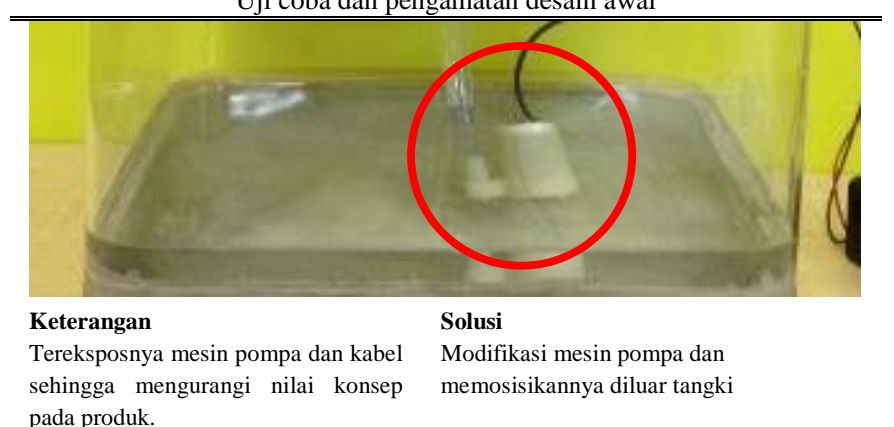

pada produk.
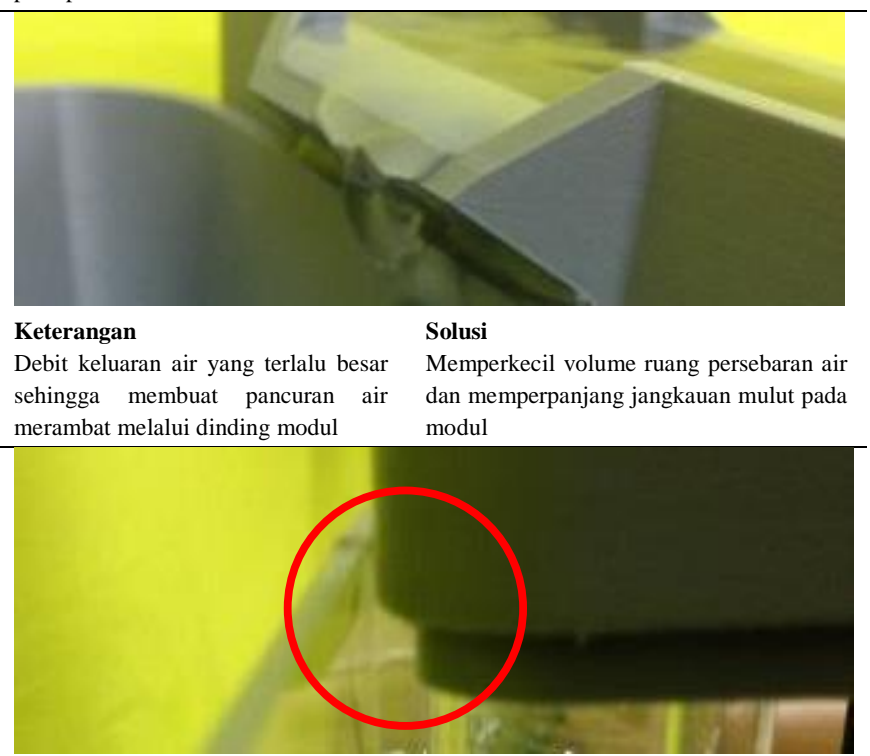

Keterangan

Solusi

Dudukan antara modul dengan mulut

akuarium yang kurang aman dan besar

terjadinya gesekan.

Memberi pengaman pada keliling mulut akuarium dan mengganti bentuk pada kaki modul

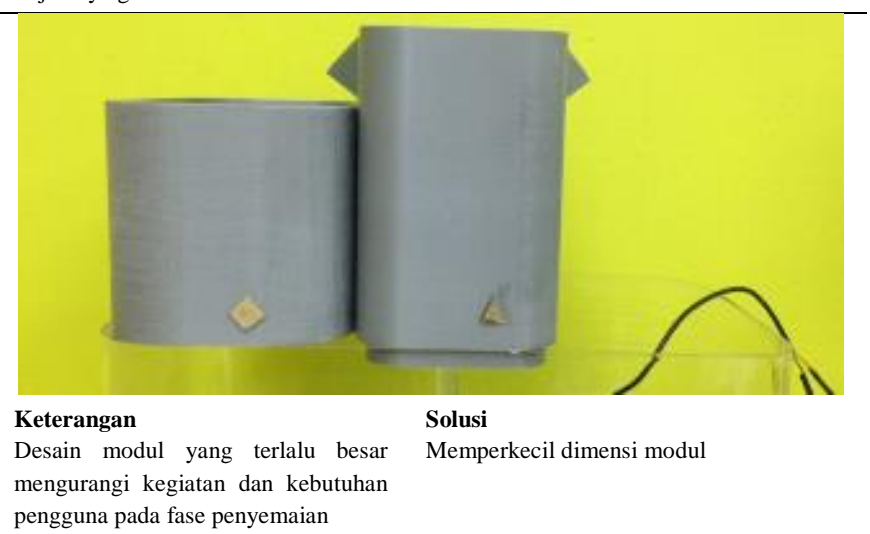

saling mengganggu pertumbuhannya. Analisis tersebut dapat dijadikan sebagai Design Requirement \& Objective.

\section{Analisis Material}

Analisis material bertujuan untuk mengetahui karakteristik suatu material yang tepat untuk produk yang akan dirancang.

Tiap material dilakukan penilaian dengan skala 1-4. Terdapat empat bagian produk yang dibuat secara terpisah. Berikut merupakan penjabaran analisis material pada bagian produk berdasarkan karakteristik material:

1) Wadah Tanaman. Wadah tanaman yang baik adalah wadah yang tahan terhadap korosi serta dapat bertahan dari adanya organisme lain seperti lumut dapat dilihat pada Tabel 3.

\section{Kesimpulan pada Tabel 3:}

Kedua material tersebut memiliki keunggulan masingmasing baik dari segi estetika pada karakter material dan daya tahan terhadap air. Namun untuk mengusung kesesuaian konsep yang direncanakan, kedua material tersebut dapat dijadikan pertimbangan sebagai series produk berikutnya.

2) Tangki Ikan. Tangki ikan yang baik adalah tangki yang memiliki daya tahan yang baik dan tidak mudah memuram dapat dilihat pada Tabel 4.

\section{Kesimpulan pada Tabel 4:}

Material akrilik dipilih berdasarkan dengan harga produksi pada manufaktur, daya lentur dan massa jenis yang ringan meskipun sebenarnya kaca memiliki nilai estetika pada segi material daripada akrilik.

3) Penyangga Lampu. Penyangga lampu dibutuhkan sebagai tempat terpasangnya komponen lampu. Penyangga lampu ini bersifat satu kesatuan dengan lampu dan menjadi modul yang terpisah dari wadah tanaman maupun tangki ikan dapat dilihat pada Tabel 5.

\section{Kesimpulan pada Tabel 5:}

Kedua material tersebut memiliki keunggulan masingmasing baik dari segi estetika pada karakter material dan daya tahan. Namun penyangga lampu ini tidak bersentuhan langsung dengan air secara terus menerus sehingga bisa saja diabaikan. Untuk mengusung kesesuaian konsep yang direncanakan, kedua material tersebut dapat dijadikan pertimbangan sebagai series produk berikutnya.

\section{Design Requirement and Objective (DR\&O)}

Setelah melakukan proses identifikasi aktivitas dan komparasi, penulis dapat menarik kebutuhan desain yang dijadikan sebagai variabel minimal, antara lain:

1) Jarak zona akar minimal sedalam $4 \mathrm{~mm}$ dari permukaan rockwool.

2) Batas air yang menggenangi rockwool sedalam $12.5 \mathrm{~mm}$ atau setengah dari rockwool untuk memberikan ruang sirkulasi udara.

3) Media tanam harus memfasilitasi ruang gerak pada akar sehingga akar dapat meraih air dengan baik, baik secara induksi maupun media lain.

4) Ruang tumbuh tanam memiliki dimensi minimal sebesar 44x50x44 mm untuk satu tanaman

5) Tanaman dapat tumbuh lebih cepat apabila diberi nutrisi tambahan dari luar.

6) Apabila tanaman terpisah dengan biofilter (teknik media bed), maka biofilter harus dipasang secara terpisah.

7) Setiap 10 gr massa ikan dibutuhkan $1 \mathrm{~L}$ air.

8) Volume untuk biofilter berukuran $1 \mathrm{~V} 2$ sampai $1 \mathrm{~L}$ per $1 \mathrm{gr}$ pakan ikan.

9) Alur air yang baik dipompa melalui akuarium, diteruskan menuju biofilter (penyaring), dan menuju akar tanaman. 
10) Proses penyemaian dan pertumbuhan daun sejati dilakukan secara terpisah dari sistem karena sistem mengaliri nutrisi.

11) Apabila sumber matahari tidak terpenuhi, cahaya artifisial dapat dijadikan sebagai alternatif (growlight).

12) Jarak antara growlight dengan tanaman setidaknya 150 $\mathrm{mm}$.

13) Spektrum yang diperlukan untuk tanaman berkisar 400 $700 \mathrm{~nm}$.

14) Spektrum warna dominan biru dengan panjang gelombang sekitar 440-490nm sangat dibutuhkan dalam proses persemaian.

15) Spektrum warna dominan merah dengan Panjang gelombang sekitar $620-780 \mathrm{~nm}$ dibutuhkan dalam proses pembungaan dan pembuahan.

16) Dibutuhkan $15 \mathrm{~W}$ LEDs untuk menerangi seluas $30 \mathrm{~cm}^{2}$ pada ketinggian lampu $30 \mathrm{~cm}$

17) Setiap penambahan jarak tinggi lampu sebanyak 30$60 \mathrm{~cm}$, akan mereduksi efektivitas lampu sebanyak $75 \%$.

\section{Kesimpulan:}

Berdasarkan hasil DRnO yang dijabarkan, dapat disimpulkan beberapa alternatif konfigurasi rancangan sistem pengairan sebagai acuan dalam mendesain seperti pada Gambar 4.

Konfigurasi tersebut merupakan hasil dari analisis berbagai metode akuaponik maupun hidroponik, sehingga metode wick system dan Akuaponik NFT dijadikan sebagai acuan dalam mendesain rancangan konfigurasi.

\section{E. Uji Coba dan Pengamatan Desain Awal}

Desain terpilih terlebih dahulu dilakukan uji coba pada sistem pengairannya, berikut merupakan analisis, pengamatan dan hasil evaluasi pada desain terpilih dapat dilihat pada Tabel 6.

\section{Kesimpulan pada Tabel 6:}

Uji coba dan pengamatan pada desain terpilih diperlukan adanya pertimbangan aspek fungsi, usabilitas, dan penampilan, sehingga pengembangan dilakukan terhadap objek pendukung yaitu mulut akuarium berupa penampan bersekat untuk membuat produk lebih aman dalam bersentuhan antar modul. Sekat tersebut dapat mempengaruhi dimensi modul tanam sehingga menghasilkan bentuk yang lebih ringkas dan modul yang digunakan menjadi lebih beragam.

\section{F. Proses Produksi}

Proses produksi difokuskan pada pembuatan façade pada produk yang menjadi tampilan utama. Bagian produk tersebut adalah penampan akuarium, mulut akuarium, dan modul tanam. Berdasarkan hasil analisis material yang telah dilakukan, produk akan menggunakan material kongkrit. Berikut adalah penjabaran proses produksi dari material kongkrit dapat dilihat pada Tabel 7 dan Gambar 5.

\section{Kesimpulan pada Tabel 7:}

Setelah mengalami proses prototyping dapat ditarik kesimpulan bahwa produk bermaterialkan kongkrit harus memiliki ketebalan dinding setidaknya $8 \mathrm{~mm}$ dan beralaskan $10 \mathrm{~mm}$. Namun dinding produk dapat diperkecil dengan
Tabel 7.

Proses Produksi

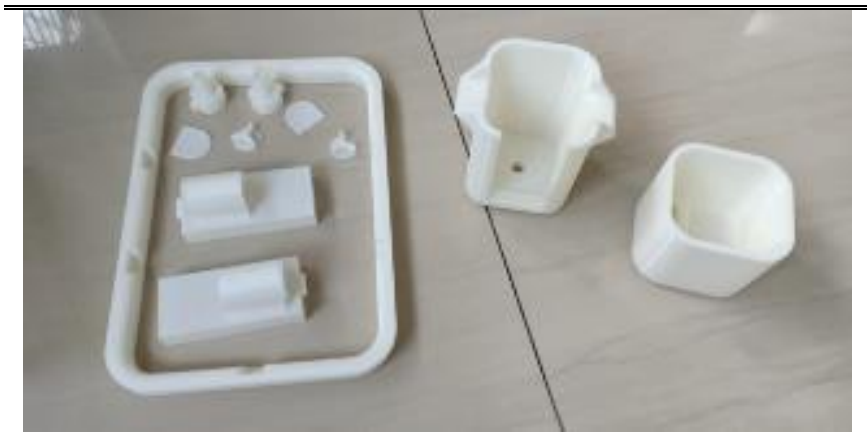

3D Modelling dilakukan dalam pembuatan secara virtual pada bagian alas, mulut, dan modul lainnya. Kemudian dikonversikan melalui software 3D print dengan lama pencetakan yang bergantung pada volume produk.

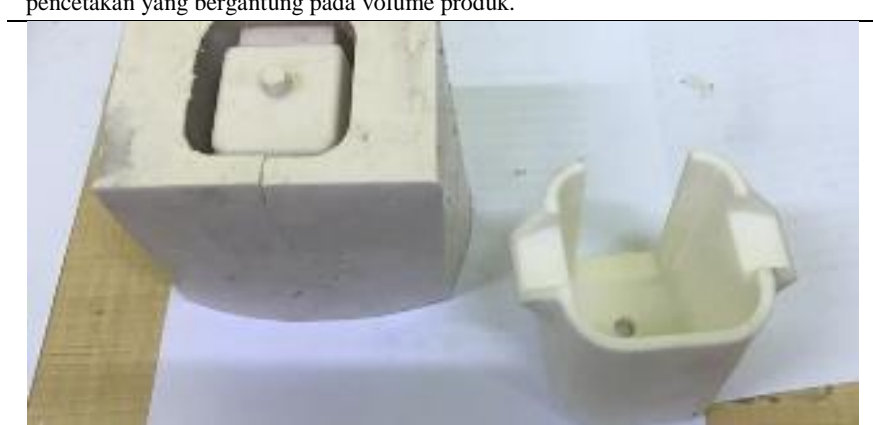

Setelah master model telah dibuat, dilanjutkan dengan proses pembuatan cetakan menggunakan silicone rubber yang dapat mengeras dengan perbandingan katalis 1:10.

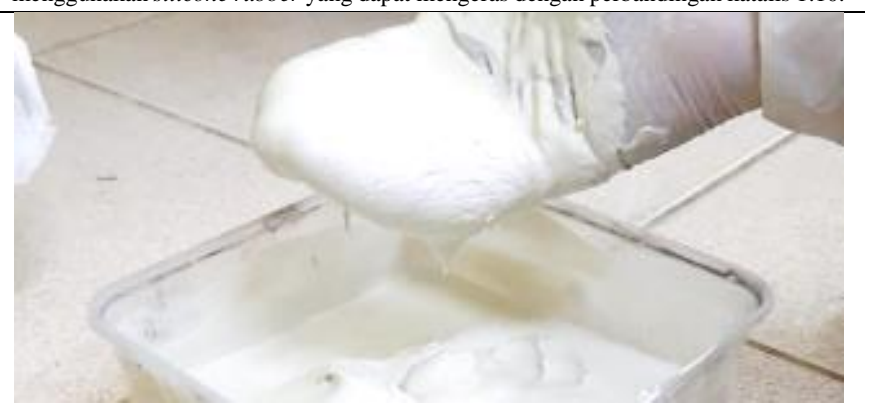

Semen putih digunakan dalam pembuatan produk kongkrit ini. Semen putih terlebih dahulu dijadikan adonan dengan pemberian air secara bertahap dan diaduk dengan konsistensi yang cukup (tidak terlalu encer).

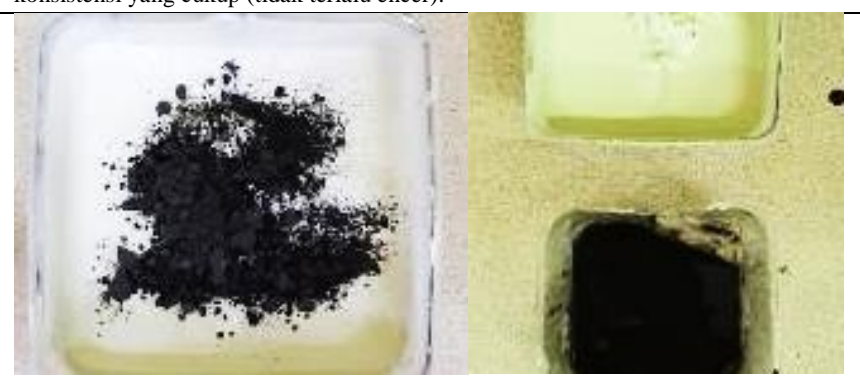

Terdapat 2 teknik dalam memberi aksen pada produk, yang pertama (gambar sebelah kiri) menggunakan kerikil dari semen nat yang sudah kering, dan kedua (gambar sebelah kanan) menggunakan semen nat yang masih dalam keadaan basah

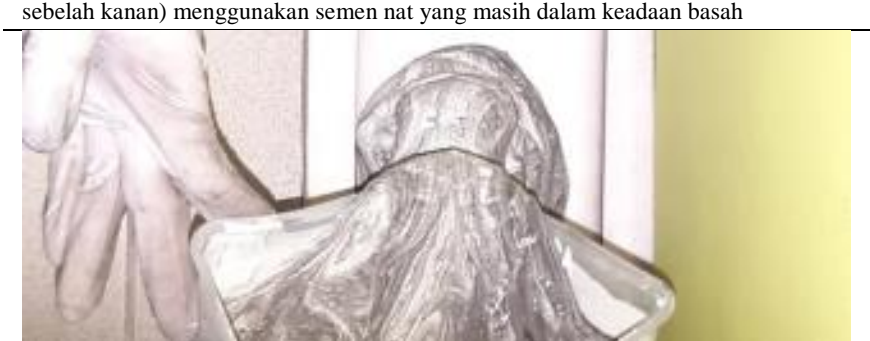


Setelah adonan telah siap, tuang adonan pada cetakan secara perlahan, untuk menghindari gelombang udara yang terperangkap, diperlukan tepukan pada cetakan secara perlahan-lahan. Setelah itu dibiarkan selama kurang lebih 24 jam.

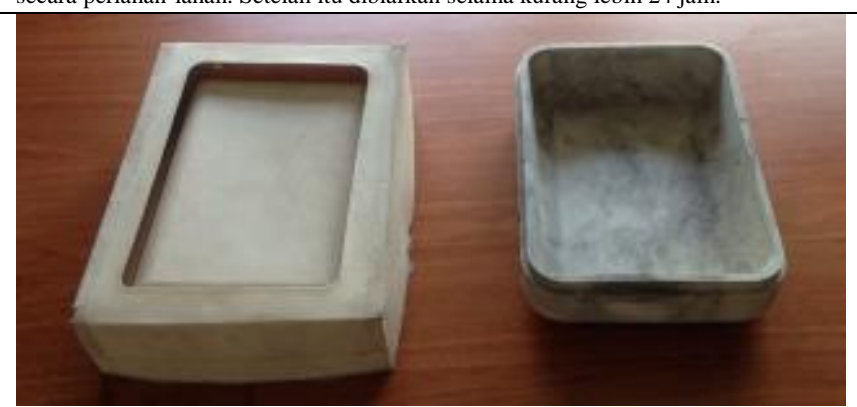

Setelah menunggu selama 24 jam, semen dapat diangkat dalam keadaan kering yang maksimal. Pengangkatan semen dapat dilakukan setiap 12 jam namun sangat tidak direkomondasikan karena produk masih terlalu beresiko mengalami pemecahan.

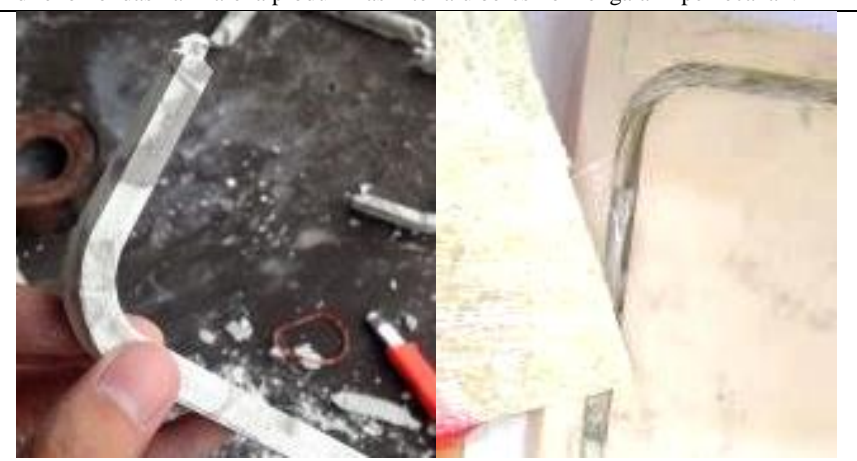

Untuk produk dengan ketebalan yang tipis seperti pada bagian mulut akuarium, perlu adanya material lain untuk mengisi bagian kerangka, seperti fiberglass atau GRC.

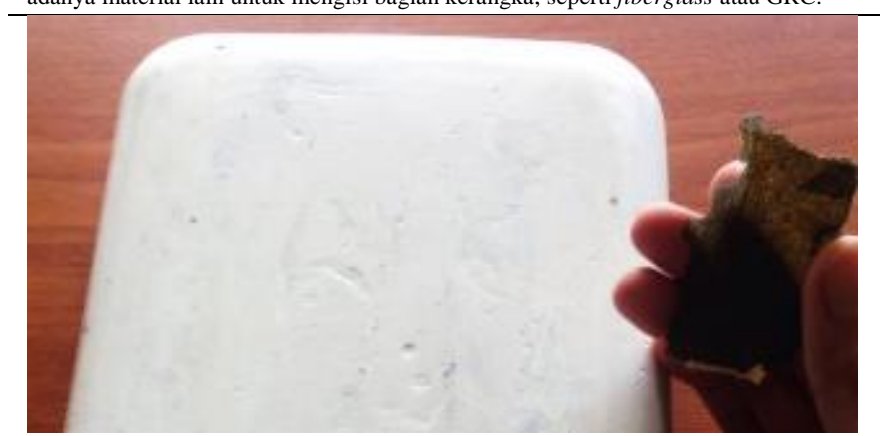

Produk diamplas secukupnya untuk mendapatkan hasil yang rapih. Amplas yang digunakan merupakan amplas sedang sekitar 200 keatas.

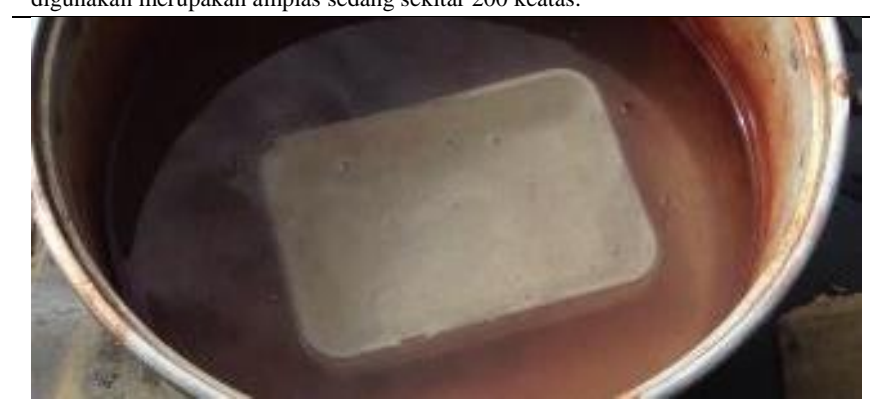

Untuk menghilangkan banyaknya debu pada produk, diperlukan perendaman dibawah terik matahari selama 5-10 menit dan dijemur selama 20 menit. Setelah itu produk masuk kedalam tahap finishing dengan minyak agar tidak merusak citra material asli. Kemudian semua bagian produk dilakukan pemasangan menjadi satu unit utuh.

mempertimbangkan bentuk yang mengerucut secara vertikal. Apabila dibutuhkan bentuk yang ekstrim dan memiliki ketebalan minimum, diperlukan material pengisi yang bersifat fleksibel dan mudah beradaptasi dengan bentuk yang akan dibuat. Berikut merupakan skema produksi selama proses prototyping.

\section{KESIMPULAN DAN SARAN}

\section{A. Kesimpulan}

Setelah melakukan proses tugas akhir ini penulis mendapatkan kesimpulan bahwa dalam melakukan kegiatan bercocok tanam tanpa tanah, harus didukung oleh peralatan dan media yang sesuai. Selain dalam penanamannya, diperlukan juga beberapa ilmu dasar agar tanaman yang ditanam dapat tumbuh dengan baik. Bagi pengguna yang mahir dalam bercocok tanam tanpa tanah ini, kegiatan tersebut dapat dijadikan sebagai hobi yang membuatnya cenderung ingin memiliki perangkat tambahan maupun penambahan instalasi lain. Semakin unik sebuah produk, semakin besar keinginan pengguna untuk dimiliki.

Plant Grower ini di desain untuk memfasilitasi kegiatan bercocok tanam bagi kalangan pemula maupun yang mahir. Produk ini hanya sebagai media pelengkap dan kit pemula dari instalasi hidroponik atau akuaponik yang besar kedalam skala kecil. Media didesain menyerupai instalasi aslinya dengan menggunakan material yang mempertimbangkan aspek desain untuk menjaga kaidah keindahan ruang yang dilengkapi dengan fitur grow light sehingga dapat diletakkan didalam ruangan.

\section{B. Saran}

Sebagai upaya dalam memudahkan pengguna dalam melakukan kegiatan bercocok tanam tanpa tanah penulis menyarankan agar:

1) Produk yang dibuat diperlukan panduan yang baik agar pengguna dapat dengan mudah memahami cara kerja produk.

2) Tidak mengabaikan teknologi pencahayaan yang sudah ada untuk disematkan kedalam fitur sehingga pemula dapat dengan mudah melakukan kegiatan bercocok tanam baik di dalam maupun luar ruangan.

3) Produk bercocok tanam tanpa tanah (soilless culture) dapat memenuhi estetika yang baik secara fisik dan visual untuk dijadikan sebagai elemen dekoratif rumah.

\section{DAFTAR PUSTAKA}

[1] N. Sharma, S. Acharya, K. Kumar, and N. Singh, "Hydroponics as an advanced technique for vegetable production: An overview," J. Soil Water Conserv., vol. 17, no. 4, pp. 364-371, 2019.

[2] C. Somerville, M. Cohen, E. Pantanella, A. Stankus, and A. Lovatelli, Small-scale aquaponic food production. Integrated fish and plant farming. Rome, Italy: FAO, 2014.

[3] W. A. Lennard and B. V. Leonard, "A Comparison of Three Different Hydroponic Sub-systems (gravel bed, floating and nutrient film technique) in an Aquaponic Test System," Aquac. Int., vol. 14, no. 6, pp. 539-550, 2006.

[4] A. Graber and R. Junge, "Aquaponic Systems: Nutrient recycling from fish wastewater by vegetable production," Desalination, vol. 246, no. 1, pp. 147-156, 2009.

[5] Y. Sastro, "Akuaponik: Budidaya Tanaman Terintegrasi Dengan Ikan, Permasalahan Keharaan dan Strategi Mengatasinya," Bul. Pertan. Perkota., vol. 5, no. 1, pp. 33-42, 2015.

[6] S. R. Surnar, O. P. Sharma, and V. P. Saini, "Aquaponics: Innovative farming," Int. J. Fish. Aquat. Stud., vol. 2, no. 4, pp. 261-263, 2015.

[7] M. Lee, J. Lee, B.-J. Park, and Y. Miyazaki, "Interaction with indoor 
plants may reduce psychological and physiological stress by suppressing autonomic nervous system activity in young adults: a randomized crossover study," J. Physiol. Anthropol., vol. 34, no. 21, 2015. 